\title{
Two cases of accidentally discovered aortic dissection
}

\section{Siniša Roginić ${ }^{1 *}$ Krešimir Štambuk², Stanko Belina'}

'General Hospital Zabok and Hospital of Croatian Veterans, Zabok, Croatia ${ }^{2}$ Magdalena Clinic for Cardiovascular Diseases, Cardiology Clinic, Krapinske Toplice, Croatia

RECEIVED:

September 3, 2017

ACCEPTED:

September 26, 2017

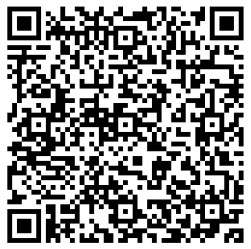

KEYWORDS: aorta, dissection, echocardiography

CITATION: Cardiol Croat. 2017;12(9-10):370-371. | https://doi.org/10.15836/ccar2017.370

*ADDRESS FOR CORRESPONDENCE: Siniša Roginić, Opća bolnica Zabok i bolnica hrvatskih veterana. Bračak 8 , HR-49210 Zabok, Croatia. / Phone: +385-98-341-234 / E-mail: sinisa.roginic@gmail.com

ORCID: Siniša Roginić, http://orcid.org/0000-0002-0384-8088 • Krešimir Štambuk, http://orcid.org/0000-0002-9107-6187 Stanko Belina, http://orcid.org/0000-0002-1872-132X

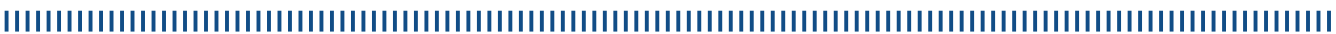

Introduction: Aortic dissection is a devastating disruption of vessel wall caused in most cases by uncontrolled hypertension or intrinsic vessel weakness. Only minority of patients have typical clinical presentation. High clinical suspicion leads to diagnosis confirmation by CT (computed tomography) and/or transesophageal echocardiography (TEE). Although TTE in not the method of choice it can surprisingly diagnose dissection and acute complications in patients referred for other reasons like in presented cases..$^{1-3}$

Case reports: 71-year old lady treated for hypertension presented with neck pain, near fainting and transitory visual loss. Diagnosis of TIA (transient ischemic attack) was established and workup included TTE showing an aneurism of thoracic and abdominal aorta with dissection flap (Figure 1). Dis-

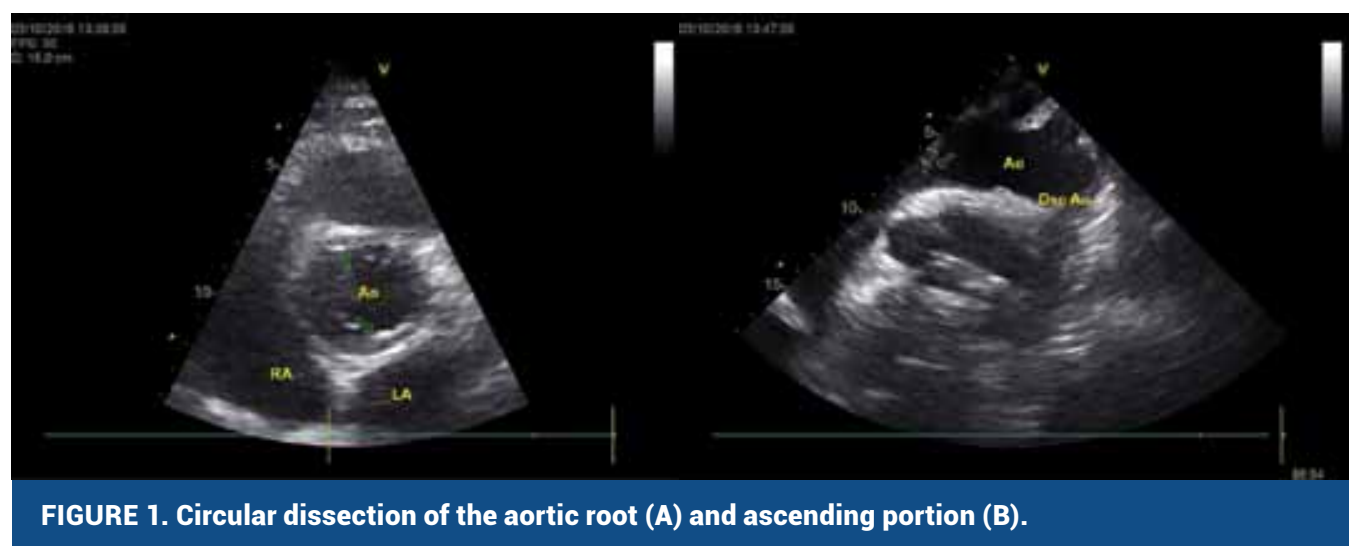

section caused moderate aortic regurgitation and propagated into brachiocephalic trunk causing neurologic symptoms. CT and TEE confirmed the diagnosis -Stanford A, DeBakey A type dissection (Figure 2). Aortic regurgitation subsided after aneurism repair so there was no need for aortic valve surgery. Postoperative recovery was prolonged by Dressler's syndrome.

Second patient was 81-year old female with hypertension and diabetes admitted to Department of Neurology ward due to syncope. Troponin values were mildly elevated and TTE was indicated. Investigation found inferoposterior wall hypokinesia (patient has had an infarction five years ago) and preserved systolic function. There was a free floating calcified mass in ascending aorta. CT confirmed dissection of thoracic aorta starting above aortic valve and reaching origin of the left subclavian artery (Stanford A, DeBakey B). Aorta was tortuous and heavily calcified therefore dissection likely started as penetrated atherosclerotic ulcer. Patient was successfully operated with uneventful postoperative recovery.

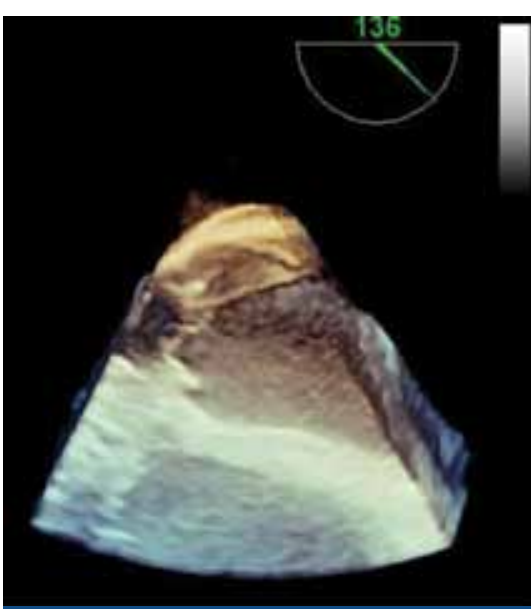

FIGURE 2. 3D transesophageal echocardiography image of dissection flap rising above the right sinus of Valsalva. 
Conclusion: Both our patients were diagnosed aortic dissection with TTE conducted for other reasons. Aortic dissection is often a lethal disease, largely due to diverse clinical presentation and delayed diagnosis. TTE is a convenient and widely available tool which can make diagnosis and hasten further management. Detailed examination of all visible aortic segments using standard and atypical views is mandatory in every patient. Sometimes accidentally, unexpected findings make big difference like in these two cases.

LITERATURE IIIIIIIIIIIIIIIIIIIIIIIIIIIIIIIIIIIIIIIIIIIIIIIIIIIIIIIIIIIIIIIIIIIIIIIIIIIIIIIIIIIIIIIIIIIIIIIIIIIIIIIIIIIIIIIIIIIIIIIIIIIIIIII

1. Hiratzka LF, Bakris GL, Beckman JA, Bersin RM, Carr VF, Casey DE Jr, et al; American College of Cardiology Foundation/American Heart Association Task Force on Practice Guidelines: American Association for Thoracic Surgery; American College of Radiology; American Stroke Association; Society of Cardiovascular Anesthesiologists; Society for Cardiovascular Angiography and Interventions; Society of Interventional Radiology; Society of Thoracic Surgeons; Society for Vascular Medicine. 2010 ACCF/AHA/AATS/ACR/ASA/SCA/SCAI/SIR/STS/ SVM guidelines for the diagnosis and management of patients with Thoracic Aortic Disease: a report of the American College of Cardiology Foundation/American Heart Association Task Force on Practice Guidelines, American Association for Thoracic Surgery, American College of Radiology, American Stroke Association, Society of Cardiovascular Anesthesiologists, Society for Cardiovascular Angiography and Interventions, Society of Interventional Radiology, Society of Thoracic Surgeons, and Society for Vascular Medicine. Circulation. 2010 Apr 6;121(13):e266-369. https://doi.org/10.1161//IR.0b013e3181d4739e

2. Erbel R, Aboyans V, Boileau C, Bossone E, Di Bartolomeo R, Eggebrecht H, et al; Authors/Task Force members. Corrigendum to: 2014 ESC Guidelines on the diagnosis and treatment of aortic diseases. Eur Heart J. 2015 Nov 1;36(41):2779. https://doi.org/10.1093/eurheartj/ehv178

3. Nienaber CA, von Kodolitsch Y, Nicolas V, Siglow V, Piepho A, Brockhoff C, et al. The diagnosis of thoracic aortic dissection by noninvasive imaging procedures. N Engl J Med. 1993 Jan 7:328(1):1-9. https://doi.org/10.1056/NEJM199301073280101 